\title{
Correction to: Cytogenotoxic and mutagenic profiling of cashew nut shell liquids and cardanol
}

Aracelli de Sousa Leite ${ }^{1}$, Muhammad Torequl Islam², Márcia Fernanda Correia Jardim Paz ${ }^{1}$, Antônio Luiz Gomes Júnior ${ }^{1}$, George Laylson da Silva Oliveira ${ }^{1}$, Antônia Maria das Graças Lopes Cito ${ }^{3}$, Ana Amélia de Carvalho Melo-Cavalcante ${ }^{1,4}$ and José Arimatéia Dantas Lopes ${ }^{1,3}$

\section{Correction to: Clin Phytosci (2019) 5:37 https://doi.org/10.1186/s40816-019-0129-8}

In the original publication of this article [1], one author's name needs to be revised from Ana Ana Amélia de Carvalho Melo-Cavalcante to Ana Amélia de Carvalho Melo-Cavalcante. This mistake is caused during the typesetting stage. The original article has been corrected.

\section{Author details}

${ }^{1}$ Northeast Biotechnology Network (RENORBIO), Postgraduate Program in Pharmaceutical Sciences, Federal University of Piauí, Teresina, PI 64009-550, Brazil. ${ }^{2}$ Department of Pharmacy, Life Science Faculty, Bangabandhu Sheikh Mujibur Rahman Science and Technology University, Gopalganj, Dhaka 8100, Bangladesh. ${ }^{3}$ Chemistry Department, CCN, Federal University of Piauí, Teresina, PI 64009-550, Brazil. ${ }^{4}$ Postgraduate Program in Pharmaceutical Sciences, Federal University of Piauí, Teresina, PI 64009-550, Brazil.

Published online: 16 December 2019

\section{Reference}

1. Leite, et al. Clin Phytosci. 2019;5:37. https://doi.org/10.1186/s40816-0190129-8.

\footnotetext{
* Correspondence: dmt.islam@bsmrstu.edu.bd

The original article can be found online at https://doi.org/10.1186/s40816019-0129-8

${ }^{2}$ Department of Pharmacy, Life Science Faculty, Bangabandhu Sheikh Mujibur Rahman Science and Technology University, Gopalganj, Dhaka 8100, Bangladesh

Full list of author information is available at the end of the article
} 